\title{
Population-based Study of Cutaneous Malignant Melanoma in the South Region of Portugal: Epidemiological and Clinical Characterization (2016-2017)
}

Filipa Alves da Costa ( $\nabla$ alvesdacosta.f@gmail.com )

Portuguese Oncology Institute

Catarina Bernardo

Portuguese Oncology Institute

Fábio Cardoso Borges

Portuguese Oncology Institute

Adriana Ramos

Portuguese Oncology Institute

Ana Costa Miranda

Portuguese Oncology Institute

\section{Research Article}

Keywords: Cancer Registry, Cutaneous melanoma, Incidence, Disease Recurrence, Survival

Posted Date: July 28th, 2021

DOI: https://doi.org/10.21203/rs.3.rs-723918/v1

License: (1) This work is licensed under a Creative Commons Attribution 4.0 International License. Read Full License 


\section{Abstract}

An historical population-based cohort study was conducted aiming to estimate the incidence of cutaneous malignant melanoma in the South Region of Portugal between Jan 2016 and June 2017; to clinically characterize the diagnosed individuals; to describe instituted treatment; and to estimate survival outcomes. Data were extracted from a cancer registry (ROR-Sul) covering 4800000 inhabitants (46\% of the Portuguese population) and included a total of 789 individuals meeting eligibility criteria. The cumulative incidence rate (18 months) of melanoma was 13.36/100,000 inhabitants and the Age-Standardized Incidence Rate per 100,000 World population was $8.43 / 100,000$ inhabitants. The most common histological subtypes identified were superficial extension, followed by malignant melanoma and nodular melanoma. Most cases were diagnosed in stage I (50.39\%), equally distributed by sex and with a median age of 65 years. During the study period, 174 recurrence events were recorded (23.45\%) and recurrence-free survival rate was significantly lower in more advanced stages. Patients had a two-fold risk of recurrence/death when in presence of ulcerated tumors [adjusted hazard ratio $($ adj HR $)=2.28 ; 95 \%$ confidence interval $(\mathrm{Cl}): 1.40-3.70]$. Overall survival rate at 3-years was $80.54 \%(77.58-83.15)$ and survival was considerably higher for individuals diagnosed at earlier stages. The epidemiologic and clinical characteristics of malignant melanoma patients studied are consistent with international literature. Treatment instituted by Portuguese clinicians is aligned with evidence-based guidelines published. The increase in the incidence rate observed suggests additional public health campaigns are needed to modify behaviours of the Portuguese population and thus reduce their risk.

\section{Introduction}

Globally, the incidence of melanoma has been increasing (1). In fact, melanoma formerly known as a rare cancer, it is currently on the top 10 most incident cancers in the US and in many other countries (2). There is controversy around the influence of sex, where some studies suggest males are at higher risk of developing melanoma (3). However, most studies indicate that sex differences must be analyzed by age groups and by doing so, there seems to be tendency towards a higher incidence in females until a certain age, which is then inverted (1) (4), possibly explained by cumulative sun exposure. Sex differences may also affect the anatomic site of tumors, as naturally women tend to more often expose lower limbs whereas males tend to expose trunks (5) (6). Various studies have shown that incidence varies also by region. In Europe for example, Nordic countries have the highest incidence and southern ones, including Portugal, Spain and Greece display the lowest values (7). These differences highlight the importance of detailed epidemiological studies comparing countries and analyzing regions within one country so that meaningful policy measures may be implemented. In fact, it is widely known today that melanoma treatment depends heavily on early diagnosis and on primary prevention so any measures that favor the adoption of responsible exposure behaviors and uptake of screening will likely contribute to improved survival (8). In the South Region of Portugal, 506 new cases of malignant melanoma were identified in 2010, and 570 in 2011, corresponding respectively to a European standardized-incidence rate of 8.05 and 9.10 per 100000 inhabitants, respectively, showing a considerable increase in just one year. Survival rates are however, also progressively increasing, with data indicating a 3-year survival rate of $85 \%$ in 2010 and $87 \%$ in 2011 (9). Of course, various factors may lead to a more reserved prognosis, namely being diagnosed at a later stage, with a more advanced level of invasion (Clark) or a greater tumor thickness (Breslow), and having some specific mutations (e.g. BRAF) (10) (11). Having a deeper knowledge of the clinical characteristics of individuals diagnosed with malignant melanoma will be important to define the necessary strategies for a timely diagnosis and for the institution of the most appropriate treatment to increase the odds of survival. Therefore, this study aimed to estimate the incidence of malignant melanoma in the South Region of Portugal in the period between Jan 2016 and June 2017; to clinically characterize the individuals with this diagnosis; to describe the treatment instituted; and to estimate survival outcomes.

\section{Materials And Methods Study Design:}


an historical population-based cohort study was set, using the South-Region Cancer Registry (ROR-Sul) to identify cases diagnosed with malignant melanoma of the skin between 01.01.2016 and 30.06.2017. The expected follow-up period was 3 years, meaning each case was followed since the date of first diagnosis for a period of three years, unless death occurred, or case was lost to follow-up (e.g. left the country).

\section{Population \& Sample}

The population of interest considered for this study is all individuals residing in the area covered by ROR-Sul.

\section{Inclusion criteria:}

Having a confirmed cutaneous malignant melanoma diagnosis; first diagnosis must have occurred within the time period defined to be of interest for study; included cases must be aged 18 years or older; and live in the area of influence of the RORSul at the moment of diagnosis.

\section{Exclusion criteria:}

not having histopathological or cytological diagnosis, according to the third revision of the International Classification of Diseases for Oncology (12).

\section{Data Sources:}

ROR-Sul is a population-based registry covering 4800000 inhabitants (46\% of the Portuguese population). Population monitoring is ensured by gathering data originating from 24 hospitals and resorting to data linkage between various sources, namely primary care centers, hospitals (including care provided and diagnostic tests made), and ultimately death certificates. Data linkage can occur by automatic data integration or by manual data entry, in both cases validated by a certified registrar. Whenever a cancer diagnosis is made, regardless of the setting, the case enters the registry and is then prospectively followed throughout the years, contacts made in every point of the health care system are captured, until death occurs. Because cases enter the registry upon diagnosis, previous exposure to risk factors is often not captured.

\section{Study variables:}

Variables considered of interest were divided into three main categories. Demographic variables comprised sex, age and district of residence at diagnosis; clinical variables referred to primary tumor location, histological subtype, stage at diagnosis (13), BRAF mutation, Clark level, Breslow index, ulceration, mitotic index, Lactate Dehydrogenase (LDH) and Eastern Cooperative Oncology Group Performance Status (ECOG PS); treatment variables considered the use of surgery, radiotherapy, other treatment (e.g., electro therapy) or systemic therapy, and combinations of the former. In addition, to these three categories, patient status during the follow-up period was also considered, namely death and disease recurrence.

\section{Statistical analysis:}

Demographic, clinical, district distribution and therapeutic characteristics were summarized as medians and interquartile ranges (IQRs) for continuous variables and as absolute and relative frequencies for categorical variables. Cumulative incidence rates at 18 months were calculated by district of residence and it has been computed the Age-Standardized Incidence Rate per 100,000 World population (ASRW) for the study region. ASRW was further categorized in three groups, defined according to the amplitude of incidence values estimated, into high ] 12.35 - 14.53], medium ]10.17 - 12.35] and low 
incidence [7.99 - 10.17], and the graphical representation in the region resorted to software GeoDa (14). The association between variables has been evaluated for study region. The $\chi 2$ test or Fish exact test was applied to evaluate the association between categorical variables, as applicable, and the t-Student test was used for continuous variables. Only variables with missing values below $20 \%$ were considered eligible for bivariate analysis, as suggested elsewhere (15). Median follow-up was computed simply, considering time between date of diagnosis and date of death or date of cut-off (3 years after date of diagnosis). Kaplan-Meier estimates have been used to assess recurrence-free survival (RFS) and overall survival (OS). Time of RFS was considered the time elapsed between date of diagnosis and date of recurrence or date of death. Disease recurrence was estimated at 3 years for stages I-III, where the event of interest was considered recurrence or metastasis following disease remission. Survival time was considered the time elapsed between date of diagnosis and date of death. For both survival analysis, for patients who do not have the event of interest were censored at last contact date or date of cutoff, as applicable. The log-rank test was used to evaluate RFS differences by stage. Multivariable Cox proportional hazards regression was used to evaluate associations between prognostic variables and RFS separated by stages (I-II and III). The proportional hazard assumptions were verified. All estimated p-values were two-sided and a 95\% confidence interval (Cl) was considered for significance. The software Stata, version 13.0, was used for all statistical analyzes (16).

\section{Ethics:}

The current study was conducted according to the principles described in Helsinki Declaration and according to the established national legislation. This implies that informed consent was obtained from all subjects when care delivery is initiated in institutions part of the ROR-Sul network. The study was approved by the institutional review board (IRB) of the Instituto Português de Oncologia de Lisboa Francisco Gentil (IPOLFG), on the 2nd July 2019 (UIC/1232).

\section{Results}

\section{Population characterization}

A total of 789 individuals were included in the analysis. The median follow-up was 36 months and follow-up completeness were $97.5 \%(n=770)$. Cases were equally divided by sex and the median age at diagnosis was 65 , similar between males and females.

The most common tumor location was trunk, immediately followed by inferior limbs. Sex was found to influence the tumor location, where most cases located in lower limbs were female (41.50\%); in comparison, trunk cases were more frequently identified in male $(45.76 \%)\left({ }^{2}=51.66\right.$; p-value $\left.<0.001\right)$. The most common histological subtypes identified were superficial spreading melanoma, followed by malignant melanoma non-otherwise specified and nodular melanoma. The latter was more common among male, whereas acral lentiginous melanoma prevailed among female. In general, females were diagnosed at earlier stages, compared to males. Ulceration was more commonly present among male, among whom higher Breslow indexes were also more frequent (Table 1). 
Demographic and clinical characteristics of cutaneous malignant melanoma cases

\begin{tabular}{|c|c|c|c|c|c|}
\hline & & & Female & Male & p-value \\
\hline \multirow[t]{2}{*}{ Sex, n (\%) } & Female & $400(50.70)$ & & & \\
\hline & Male & $389(49.30)$ & & & \\
\hline \multicolumn{2}{|l|}{ Age, median $\{Q 25-Q 75\}$} & $65\{52-75\}$ & & & \\
\hline \multicolumn{2}{|l|}{ Age, mean } & 63.24 & 62.38 & 64.14 & 0.115 \\
\hline \multirow[t]{5}{*}{ Primary tumor location, n (\%) } & Trunk & $290(36.76)$ & $112(28.00)$ & $178(45.76)$ & \multirow[t]{5}{*}{$<0.001^{\star}$} \\
\hline & Inferior limbs & $237(30.04)$ & $166(41.50)$ & $71(18.25)$ & \\
\hline & Superior limbs and shoulders & $129(16.35)$ & $69(17.25)$ & $60(15.42)$ & \\
\hline & Face & $67(8.49)$ & $32(8.00)$ & $35(9.00)$ & \\
\hline & Other locations & $66(8.37)$ & $21(5.25)$ & $45(11.57)$ & \\
\hline \multirow[t]{5}{*}{ Histological subtype, n (\%) } & Superficial spreading & $419(53.11)$ & $218(54.50)$ & 201(53.11) & \multirow[t]{5}{*}{0.052} \\
\hline & Malignant melanoma NOS & $149(18.88)$ & 79 (19.75) & 70 (17.99) & \\
\hline & Nodular melanoma & $135(17.11)$ & $55(13.75)$ & $80(20.57)$ & \\
\hline & Acral lentiginous melanoma & $40(5.07)$ & $26(6.50)$ & $14(3.60)$ & \\
\hline & Other subtypes & $46(5.83)$ & $22(5.50)$ & $24(6.17)$ & \\
\hline \multirow{4}{*}{$\begin{array}{l}\text { Stage at diagnosis, } \mathrm{n}(\%) \\
\text { Unknown, } \mathrm{n}=13\end{array}$} & 1 & 391 (50.39) & $227(57.61)$ & $164(42.93)$ & \multirow[t]{4}{*}{$<0.001^{*}$} \\
\hline & $\|$ & $216(27.84)$ & $100(25.38)$ & $116(30.37)$ & \\
\hline & III & $135(17.40)$ & $56(14.21)$ & 79 (20.68) & \\
\hline & IV & $34(4.31)$ & $11(2.79)$ & $23(6.02)$ & \\
\hline \multirow{2}{*}{$\begin{array}{l}\text { Ulceration, n (\%) } \\
\text { Unknown, n = } 26\end{array}$} & Yes & $230(30.14)$ & 102 (26.09) & $128(34.41)$ & \multirow[t]{2}{*}{$0.012^{\star}$} \\
\hline & No & $533(69.86)$ & $289(73.91)$ & $244(65.59)$ & \\
\hline \multirow{4}{*}{$\begin{array}{l}\text { Breslow index, } \mathrm{n}(\%) \\
\text { Unknown, } \mathrm{n}=37\end{array}$} & $\leq 0.75 \mathrm{~mm}$ & $256(34.04)$ & $143(37.14)$ & $113(30.79)$ & \multirow[t]{4}{*}{$0.002^{\star}$} \\
\hline & ]0.75-1.50] mm & $139(18.48)$ & $85(22.08)$ & $54(14.71)$ & \\
\hline & ]1.50-4.00] mm & $190(25.27)$ & $83(21.56)$ & $107(29.16)$ & \\
\hline & $>4.00 \mathrm{~mm}$ & $167(21.21)$ & $74(19.22)$ & $93(25.34)$ & \\
\hline \multicolumn{6}{|c|}{ *signals statistically significant differences } \\
\hline \multicolumn{6}{|c|}{$\begin{array}{l}\text { Acronyms used in the table: ECOG PS, Eastern Cooperative Oncology Group Performance Status; LDH, Lactate } \\
\text { dehydrogenase; NOS Non-Otherwise Specified }\end{array}$} \\
\hline
\end{tabular}

Among the 189 individuals evaluated for the presence of BRAF mutations, $61.38 \%(n=116)$ were wild type (missing $n=600$; $76.05 \%$ ). Mitotic index was below $1 \mathrm{~mm} 2$ for 280 cases (50.45\%); missing information for this variable was present in 234 cases $(29.66 \%)$. LDH was normal in most cases $(n=245 ; 92.11 \%)$, even though for 523 cases this data was missing (66.29\%). Clark level was also missing for 273 cases (34.60\%); for those evaluated level II was identified in 135 cases (26.16\%), level III in 145 cases (28.10\%), level IV in 193 cases (37.40\%) and level V in 43 cases (8.33\%). Finally, ECOG PS was the fifth and final variable not possible to consider for bivariate analysis. Missing values were identified in 337 cases (42.71\%); in the remaining, the most common was to have PS 0 or 1 ( $n=426 ; 94.25 \%)$. 


\section{Incidence Rate}

The cumulative incidence rate (18 months) of cutaneous melanoma in the South Region was 13.36/100,000 inhabitants and the ASRW was 8.43/100,000 inhabitants. High incidence regions were Lisbon, Évora, Setúbal, Faro and Santarém, with values ranging from 12.40 to 14.53 . Low incidence regions were Madeira Autonomous region and Portalegre, with values of 7.99 and 9.34 respectively. The remaining regions (Leiria* and Beja) were classified as medium incidence regions [figure 1].

\section{Treatment patterns}

Most patients in this cohort were subject solely to surgery $(n=699 ; 88.59 \%)$. At stages I and II, most patients had only their primary tumour excised $(n=376 ; 63.62 \%)$ or were subject to the removal of the sentinel ganglion $(n=209 ; 34.43 \%)$. At stages III, most patients were also exclusively treated by surgery $(n=90 ; 66.67 \%)$ and a relevant proportion by surgery and radiotherapy $(n=26 ; 19.26 \%)$. A high proportion of patients at stage IV did not receive any treatment $(n=9 ; 26.47 \%)$, while among the remaining, the most common was to have surgery exclusively $(n=8 ; 23.53 \%)$ or in combination with systemic therapy $(n=7 ; 20.59 \%)$, or other forms of treatment $(n=8 ; 23.53 \%)$ (Table 2$)$. 
Table 2

Treatment patterns for cutaneous malignant melanoma cases in ROR-Sul

\begin{tabular}{|c|c|c|c|c|c|c|}
\hline Treatment patterns & $\begin{array}{l}\text { ROR-Sul, } \\
(n=789)\end{array}$ & $\begin{array}{l}\text { Stage I } \\
(n= \\
391)\end{array}$ & $\begin{array}{l}\text { Stage II } \\
(n= \\
216)\end{array}$ & $\begin{array}{l}\text { Stage III } \\
(n= \\
135)\end{array}$ & $\begin{array}{l}\text { Stage IV } \\
(n=34)\end{array}$ & $\begin{array}{l}\text { Unknown } \\
(n=13)\end{array}$ \\
\hline Surgery only, n (\%) & $\begin{array}{l}699 \\
(88.59)\end{array}$ & $\begin{array}{l}379 \\
(96.93)\end{array}$ & $\begin{array}{l}212 \\
(98.15)\end{array}$ & $\begin{array}{l}90 \\
(66.67)\end{array}$ & $\begin{array}{l}8 \\
(23.53)\end{array}$ & $\begin{array}{l}10 \\
(76.92)\end{array}$ \\
\hline Excising of primary tumour & $\begin{array}{l}394 \\
(56.37)\end{array}$ & $\begin{array}{l}273 \\
(72.03)\end{array}$ & $\begin{array}{l}103 \\
(48.58)\end{array}$ & $\begin{array}{l}6 \\
(6.67)\end{array}$ & $\begin{array}{l}5 \\
(62.50)\end{array}$ & $\begin{array}{l}7 \\
(70,00)\end{array}$ \\
\hline $\begin{array}{l}\text { Excising of primary tumour and sentinel } \\
\text { ganglion }\end{array}$ & $\begin{array}{l}209 \\
(29.90)\end{array}$ & $\begin{array}{l}93 \\
(24.54)\end{array}$ & $\begin{array}{l}100 \\
(47.17)\end{array}$ & $\begin{array}{l}13 \\
(14.44)\end{array}$ & $\begin{array}{l}1 \\
(12.50)\end{array}$ & $\begin{array}{l}2 \\
(20.00)\end{array}$ \\
\hline $\begin{array}{l}\text { Excising of primary tumour, sentinel ganglion } \\
\text { and } \\
\text { lymphadenectomy }\end{array}$ & $\begin{array}{l}78 \\
(11.16)\end{array}$ & $\begin{array}{l}11 \\
(2.90)\end{array}$ & $\begin{array}{l}5 \\
(2.36)\end{array}$ & $\begin{array}{l}61 \\
(67.78)\end{array}$ & - & $\begin{array}{l}1 \\
(10.00)\end{array}$ \\
\hline Other & $\begin{array}{l}18 \\
(2.58)\end{array}$ & $\begin{array}{l}2 \\
(0.53)\end{array}$ & $\begin{array}{l}4 \\
(1.89)\end{array}$ & $\begin{array}{l}10 \\
(11.11)\end{array}$ & $\begin{array}{l}2 \\
(25.00)\end{array}$ & - \\
\hline Surgery and radiotherapy, n (\%) & $\begin{array}{l}30 \\
(3.80)\end{array}$ & $\begin{array}{l}1 \\
(0.26)\end{array}$ & $\begin{array}{l}2 \\
(0.93)\end{array}$ & $\begin{array}{l}26 \\
(19.26)\end{array}$ & $\begin{array}{l}1 \\
(2.94)\end{array}$ & - \\
\hline $\begin{array}{l}\text { Excising of primary tumour, lymphadenectomy + } \\
\text { radiotherapy }\end{array}$ & $\begin{array}{l}13 \\
(43.33)\end{array}$ & - & - & $\begin{array}{l}13 \\
(50.00)\end{array}$ & $\begin{array}{l}0 \\
(0.00)\end{array}$ & - \\
\hline $\begin{array}{l}\text { Excising of primary tumour, sentinel ganglion } \\
\text { and lymphadenectomy + radiotherapy }\end{array}$ & $\begin{array}{l}11 \\
(36.67)\end{array}$ & - & - & $\begin{array}{l}11 \\
(42.31)\end{array}$ & - & - \\
\hline Excising of primary tumour + radiotherapy & $\begin{array}{l}5 \\
(16.67)\end{array}$ & $\begin{array}{l}1 \\
(100)\end{array}$ & $\begin{array}{l}2 \\
(100)\end{array}$ & $\begin{array}{l}1 \\
(3.85)\end{array}$ & $\begin{array}{l}1 \\
(100)\end{array}$ & - \\
\hline Other & $\begin{array}{l}1 \\
(3.33)\end{array}$ & - & - & $\begin{array}{l}1 \\
(3.85)\end{array}$ & - & - \\
\hline Surgery and systemic treatment, $\mathrm{n}(\%)$ & $\begin{array}{l}21 \\
(2.66)\end{array}$ & - & $\begin{array}{l}1 \\
(0.46)\end{array}$ & $\begin{array}{l}13 \\
(9.63)\end{array}$ & $\begin{array}{l}7 \\
(20.59)\end{array}$ & - \\
\hline $\begin{array}{l}\text { Excising of primary tumour, sentinel ganglion } \\
\text { and lymphadenectomy + Interferon }\end{array}$ & $\begin{array}{l}5 \\
(23.81)\end{array}$ & - & - & $\begin{array}{l}5 \\
(38.46)\end{array}$ & - & - \\
\hline $\begin{array}{l}\text { Excising of primary tumour, sentinel ganglion } \\
\text { and lymphadenectomy + Clinical trial }\end{array}$ & $\begin{array}{l}3 \\
(14.29)\end{array}$ & - & - & $\begin{array}{l}3 \\
(23.08)\end{array}$ & - & - \\
\hline $\begin{array}{l}\text { Excising of primary tumour + Anti-PD-1/Anti-PD- } \\
\text { L1 }\end{array}$ & $\begin{array}{l}3 \\
(14.29)\end{array}$ & - & - & - & $\begin{array}{l}3 \\
(42.86)\end{array}$ & - \\
\hline $\begin{array}{l}\text { Other (anti-MEK, anti-BRAF, classical } \\
\text { chemotherapy and combinations) }\end{array}$ & $\begin{array}{l}10 \\
(47.62)\end{array}$ & - & $\begin{array}{l}1 \\
(100)\end{array}$ & $\begin{array}{l}5 \\
(38.46)\end{array}$ & $\begin{array}{l}4 \\
(57.14)\end{array}$ & - \\
\hline
\end{tabular}

Acronyms used in the table: ROR-Sul, South-Region Cancer Registry 


\begin{tabular}{|c|c|c|c|c|c|c|}
\hline Treatment patterns & $\begin{array}{l}\text { ROR-Sul, } \\
(n=789)\end{array}$ & $\begin{array}{l}\text { Stage I } \\
(n= \\
391)\end{array}$ & $\begin{array}{l}\text { Stage II } \\
(n= \\
216)\end{array}$ & $\begin{array}{l}\text { Stage III } \\
(n= \\
135)\end{array}$ & $\begin{array}{l}\text { Stage IV } \\
(n=34)\end{array}$ & $\begin{array}{l}\text { Unknown } \\
(n=13)\end{array}$ \\
\hline $\begin{array}{l}\text { Other treatment (cryotherapy, laser therapy, } \\
\text { nuclear medicine, electrotherapy, and retinoic } \\
\text { acid) }\end{array}$ & $\begin{array}{l}14 \\
(1.77)\end{array}$ & - & $\begin{array}{l}1 \\
(0.46)\end{array}$ & $\begin{array}{l}5 \\
(3.70)\end{array}$ & $\begin{array}{l}8 \\
(23.53)\end{array}$ & - \\
\hline Without treatment, n (\%) & $\begin{array}{l}23 \\
(2.92)\end{array}$ & $\begin{array}{l}11 \\
(2.81)\end{array}$ & - & - & $\begin{array}{l}9 \\
(26.47)\end{array}$ & $\begin{array}{l}3 \\
(23.08)\end{array}$ \\
\hline
\end{tabular}

Among the 23 patients that did not receive any treatment $(2.92 \%)$, the most common reasons were death $(n=6)$ or patient refusal $(n=3)$; in 11 patients the reason was unknown.

\section{Disease recurrence}

During the study period, there were 174 recurrence/death events recorded (23.45\%). Recurrence-free survival rate was significantly lower in more advanced stages $(p<0.001)$ (Table 3$)$.

Table 3

Recurrence of stages I-III cutaneous melanoma at 3 years

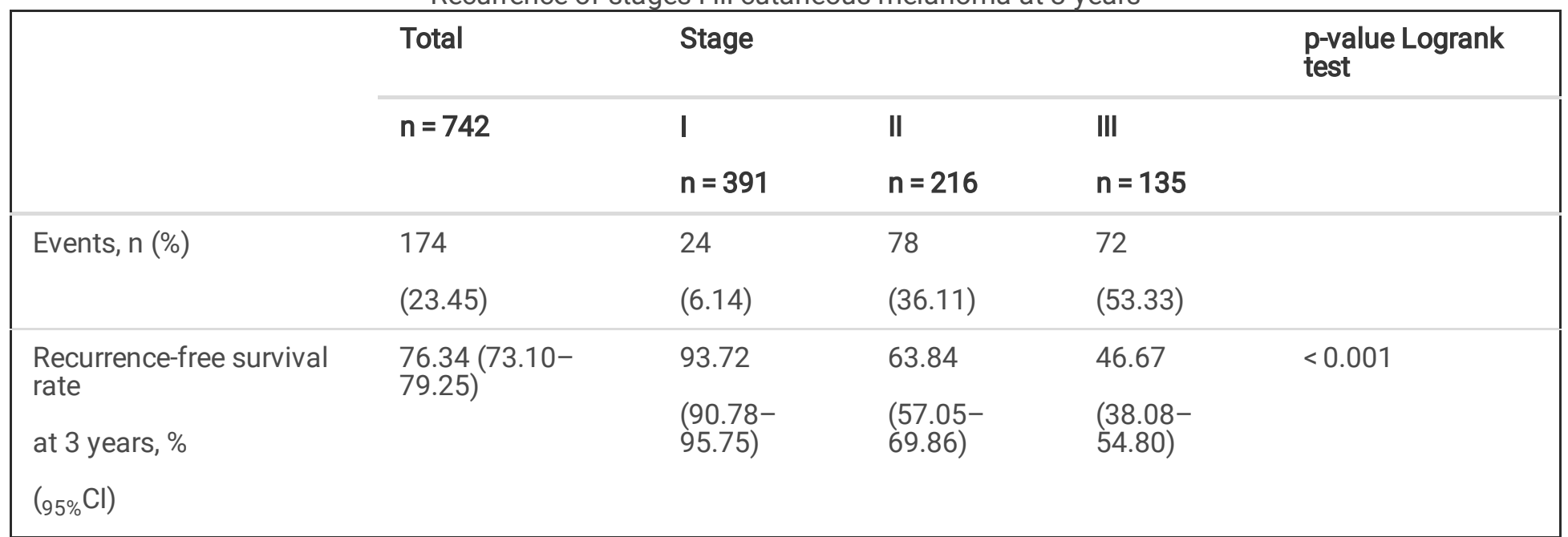

Multivariate regression analysis for patients with stages I-II at diagnosis, adjusted for age, demonstrated that presence of ulcerated tumors [adjusted hazard ratio $(\operatorname{adj~HR})=2.87 ; 95 \%$ confidence interval $(\mathrm{Cl}): 1.81-4.54$ ] and Breslow index above 4 mm (adj HR = 5.94; 95\% Cl: 4.01-8.81) were associated with a higher risk of recurrence/death. Additionally, multivariate regression analysis for individuals diagnosed at stage III, with the same adjustment variable considered in the previous model, indicated that patients had a two-fold increased risk of recurrence/death when in presence of ulcerated tumors (adj $\mathrm{HR}=2.28 ; 95 \% \mathrm{Cl}: 1.40-3.70)$ (Table 4). Figure 2 presents recurrence-free survival by stage. 
Table 4

Recurrence-Free Survival of cutaneous melanoma by stage (I-II and III) - univariate and multivariate cox regression analysis

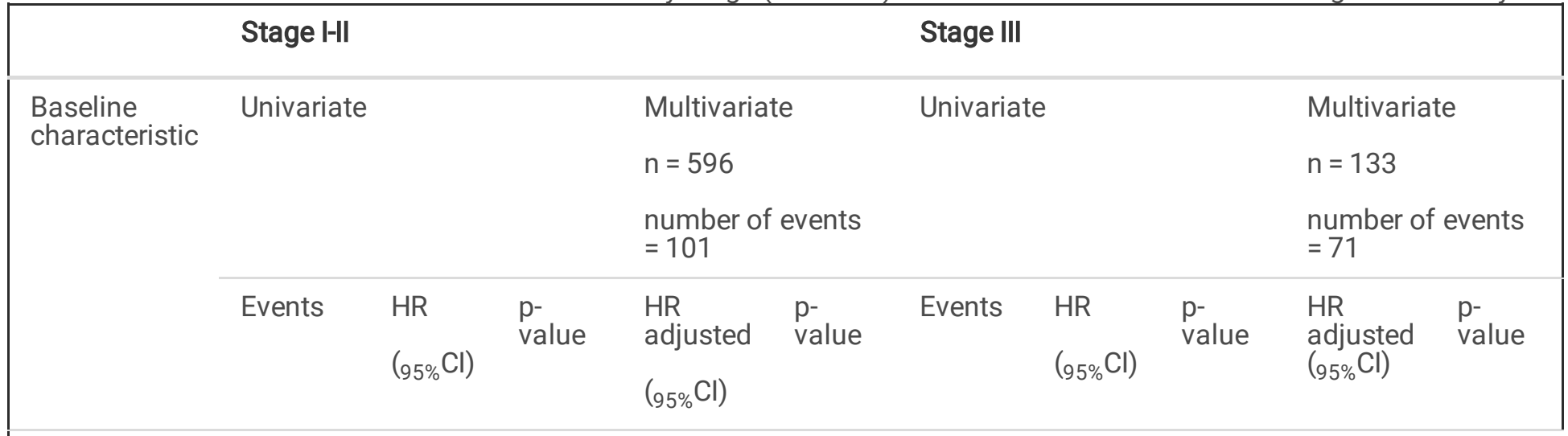

Sex

\begin{tabular}{|c|c|c|c|c|c|c|c|c|c|}
\hline $\begin{array}{l}\text { Female } \\
\text { (reference) }\end{array}$ & $102 / 607$ & 1 & 0.237 & - & - & $\begin{array}{l}72 / \\
135\end{array}$ & 1 & 0.831 & - \\
\hline \multirow[t]{2}{*}{ Male } & & 1.26 & & - & - & & 0.95 & & - \\
\hline & & $\begin{array}{l}(0.86- \\
1.86)\end{array}$ & & & & & $\begin{array}{l}(0.60- \\
1.52)\end{array}$ & & \\
\hline
\end{tabular}

Age (years)

\begin{tabular}{|c|c|c|c|c|c|c|c|c|c|c|}
\hline $\begin{array}{l}18-40 \\
\text { (reference) }\end{array}$ & $102 / 607$ & 1 & $\begin{array}{l}< \\
0.001 *\end{array}$ & 1 & & 72/135 & 1 & $\begin{array}{l}< \\
0.001\end{array}$ & 1 & \\
\hline \multirow[t]{2}{*}{$41-65$} & & 1.64 & & 1.22 & 0.745 & & 1.02 & & 1.04 & 0.934 \\
\hline & & $\begin{array}{l}(0.49- \\
5.47)\end{array}$ & & $\begin{array}{l}(0.36- \\
4.08)\end{array}$ & & & $\begin{array}{l}(0.43- \\
2.42)\end{array}$ & & $\begin{array}{l}(0.43- \\
2.46)\end{array}$ & \\
\hline \multirow[t]{2}{*}{$\geq 66$} & & 5.25 & & 2.66 & 0.102 & & 2.22 & & 1.74 & 0.180 \\
\hline & & $\begin{array}{l}(1.66- \\
16.64)\end{array}$ & & $\begin{array}{l}(0.82- \\
8.58)\end{array}$ & & & $\begin{array}{l}(1.00- \\
4.93)\end{array}$ & & $\begin{array}{l}(0.78- \\
3.89)\end{array}$ & \\
\hline
\end{tabular}

Histological

subtype

\begin{tabular}{|c|c|c|c|c|c|c|c|c|c|c|}
\hline $\begin{array}{l}\text { Nodular } \\
\text { melanoma } \\
\text { (M8721/3) } \\
\text { (reference) }\end{array}$ & $102 / 607$ & 1 & $\stackrel{<}{0.001 *}$ & - & - & $72 / 135$ & 1 & $0.003^{*}$ & - & - \\
\hline \multirow{2}{*}{$\begin{array}{l}\text { Superficial } \\
\text { spreading } \\
\text { (M8743/3) }\end{array}$} & & 0.22 & & - & - & & 0.46 & & - & - \\
\hline & & $\begin{array}{l}(0.14- \\
0.35)\end{array}$ & & & & & $\begin{array}{l}(0.25- \\
0.83)\end{array}$ & & & \\
\hline \multirow[t]{2}{*}{ Others } & & 0.31 & & - & - & & 1,18 & & - & - \\
\hline & & $\begin{array}{l}(0.19- \\
0.52)\end{array}$ & & & & & $\begin{array}{l}(0.69- \\
2.02)\end{array}$ & & & \\
\hline
\end{tabular}

Breslow

$101 / 596 \quad 1$

$<\begin{array}{llllll}< & <1 / 133 & 1 & 0.001 * & 1\end{array}$

0.081

(reference)

a Categories: $<0.75 \mathrm{~mm}$; $>0.75-1.50 \mathrm{~mm}$ e $>1.50-4.00 \mathrm{~mm}$; * Statistically significant difference. Acronyms used in the table: HR, Hazard Ratio; $\mathrm{Cl}$, confidence interval 


\begin{tabular}{|c|c|c|c|c|c|c|c|c|c|c|}
\hline & Stage I-II & & & & & Stage III & & & & \\
\hline \multirow[t]{2}{*}{$\begin{array}{l}\text { IV [> } 4.00 \\
\mathrm{~mm}]\end{array}$} & & 6.59 & & 2.87 & & & 2.28 & & 1.60 & \\
\hline & & $\begin{array}{l}(4.45- \\
9.77)\end{array}$ & & $\begin{array}{l}(1.81- \\
4.54)\end{array}$ & & & $\begin{array}{l}(1.40- \\
3.70)\end{array}$ & & $\begin{array}{l}(0.94- \\
2.69)\end{array}$ & \\
\hline Ulceration & \multirow{4}{*}{$102 / 607$} & & & & & & & & & \\
\hline $\begin{array}{l}\text { No } \\
\text { (reference) }\end{array}$ & & 1 & $<.001 *$ & 1 & & 71/133 & 1 & $0.001 *$ & 1 & $0.022^{*}$ \\
\hline \multirow[t]{2}{*}{ Yes } & & 5.94 & & 3.21 & \multirow{2}{*}{$<.001 *$} & & 2.52 & & 1.94 & \\
\hline & & $\begin{array}{l}(4.01- \\
8.81)\end{array}$ & & $\begin{array}{l}(2.02- \\
5.08)\end{array}$ & & & $\begin{array}{l}(1.47- \\
4.31)\end{array}$ & & $\begin{array}{l}(1.10- \\
3.44)\end{array}$ & \\
\hline
\end{tabular}

\section{Survival}

During the study period, there were 152 death events recorded (19.26\%). Overall survival rate at 3-years was $80.54 \%$ (77.5883.15). Survival was considerably higher for individuals diagnosed at earlier stages. Median OS was not reached at 3-years [figure 3].

\section{Discussion}

The main findings of this stage indicate that in the South Region of Portugal, the median age of diagnosis of cutaneous melanoma is 65 years and that $50 \%$ of all cases in the study period were diagnosed at ages between 52 and 75 years of age, in line with previously published data (17) (18).

The location of the primary tumour identified in this study and its distribution by gender is as expected by previous research and possibly explained by behaviour of sun exposure adopted by men and women (19) (1) (2) (20). Previous national studies have also reported differences in the location of the primary tumour by gender (21).

The incidence rate at one year $(8.43 / 100,000$ inhabitants) was higher than reported four years earlier for the same region (7.65/100,000 inhabitants) (9) and could possibly be explained by an increase in incidence of malignant melanoma, as described in other countries (22) (23). Within-country differences in incidence rates could be explained by the different sun exposure patterns and by varied screening practices adopted. In fact, the region with the highest incidence identified is the capital, where more intense screening activities have been made available since 2016 between April and October, coinciding with the beach season. As a result, individuals identified in these metropolitan areas were more commonly diagnosed at an earlier stage, hence having a better disease prognosis.

Notwithstanding, the data also suggests that most cases are diagnosed at early stages, as described in Portugal and also in Sweden (17) (21). 
The Oncology Register does not collect information on risk behaviors. The reason for this is that the inclusion of cases in the register is initiated by the diagnosis, thus no previous information is collected. Most of the variables explored in terms of risk factors have ample evidence, namely sun exposure and screening practices and therefore this may not be considered a study limitation.

Treatment patterns observed are aligned with European guidelines published in 2015, recommending surgery in earlier stages (I and II), combined with systemic therapy or radiotherapy in more advanced stages (III) or exclusively for metastatic disease (IV) (24). The fact that only around $25 \%$ of patients had BRAF mutation determined is not surprising as in fact, such analysis is only considered crucial for the selection of targeted therapy (25) (26). This explains why most cases where BRAF mutation was determined were at more advanced stages. Among individuals tested for this mutation, around $40 \%$ had a positive result, slightly inferior but still in line with data published for Russia and Denmark (27) (28) and considerably different from reported for Asia (29) (30), which may be a result of the different genomic characteristics of these populations.

To the authors' best knowledge, there is no national data published on disease recurrence for melanoma, against which our data may be compared. However, the higher recurrence observed at more advanced stages was expected.

This study is innovative and provides valuable data that enables epidemiologic and clinical characterization of malignant melanoma in Portugal. The high coverage of this population-based register, which resorts to data linkage systems, is undoubtedly a strong point of the study, and contributes to the external validity of data presented. It is also worth noting the proportion of follow-up completeness (97.5\%), extremely relevant to characterize the outcomes of interest (OS and RFS).

\section{Limitations}

Some of the limitations of this study include its retrospective nature. The low exhaustiveness of some of the variables has been reported elsewhere (31), and did not allow important prognostic variables, such as LDH and mitotic index, to be included in bivariate and multivariate analysis.

\section{Conclusion}

The epidemiologic and clinical characteristics of malignant melanoma patients included in this study are consistent with the international literature. An increase in the incidence rate was observed in a period of 5 years, suggesting additional public health campaigns are needed to modify behaviours of the Portuguese population and thus reduce their risk. The institution of treatment followed by Portuguese clinicians is aligned with evidence-based guidelines published.

\section{Declarations}

\section{Funding:}

the study was financed by Novartis Portugal SA. The company had no role or interference in the definition of the study methods, analysis conducted or in the manuscript produced as a result.

\section{Conflicts of interest/Competing interests:}

none declared

\section{Availability of data and material:}

all data included is available in an anonymized manner upon reasonable request. 


\section{Code Availability:}

GeoDa. release 1.12.1.131 and StataCorp. . Stata Statistical Software. College Station, TX : StataCorp LP. , 2013. Release 13.

\section{Author's contributions:}

ACM conceived the study, supervised its execution, revised and approved the manuscript. FCB and CB reviewed records and supported AR in data analysis and interpretation. AR extracted data and analyzed it. FAC contributed to the study design and supervision, interpretation of data, and wrote the manuscript. All authors reviewed and approved the manuscript.

\section{Acknowledgments:}

to the cancer coordinators of all the hospitals integrating the South Regional Register for their contribution to the exhaustiveness and update of all data included.

\section{References}

1. MacKie, R. M., Hauschild, A. \& Eggermont, A. M. Epidemiology of invasive cutaneous melanoma. Ann Oncol. 20 de 2009, pp. 1-7.

2. Rastrelli, M., Saveria, T., Rossi, C. R. \& Melanoma, A. M. Epidemiology, Risk Factors, Pathogenesis, Diagnosis and Classification. in vivo. 28 de 2014, pp. 1005-1012.

3. Markovic, S. N. et al. and. Malignant melanoma in the 21st century, part 1: epidemiology, risk factors, screening, prevention and diagnosis.. Mayo Clin Proc. 3 de 2007, pp. 364-380.

4. Rigel, D. S. Epidemiology of melanoma. Semin Cutan Med Surg. 4 de 2010, pp. 204-209.

5. Elwood, J. M. \& Gallager, R. P. Body site distribution of cutaneous melanoma in relationship to patterns of sun exposure. Int J Cancer. 78 de 1998, pp. 276-280.

6. Ocaña-Riola, R. et al. Population-based study of cutaneous malignant melanoma in the Granada province (Spain), 1985-1992. European Journal of Epidemiology. 17 de 2001, pp. 169-174.

7. Ferlay, J. EUCAN90: Cancer in the European Union (IARC, Lyon, 1996).

8. Parkin, D. M., Wagner, G. \& Muir, C. S. The Role of the Registry in Cancer Control. Lyon: IARC Scientific Publications 1985.

9. Registo Oncológico Regional Sul. Incidência, sobrevivência e mortalidade por cancro na região sul de portugal - ISM 2012 (Registo Oncológico Regional Sul, Lisboa, 2020).

10. Wu, X. et al. Mutations in BRAF codons 594 and 596 predict good prognosis in melanoma. Oncol Lett, Vol. 14, 3360133605 (2017).

11. Boland, G. M. \& Gershenwald, J. E. Principles of melanoma staging. Cancer Treatment and Research.2016, pp.133-134.

12. World Health Organization. International classification of diseases for oncology (ICD-O). Geneva: WHO Library Cataloguing-in-Publication Data, 2013. Vols. 3rd edition, 1st revision. $9789241548496 \$ 4$

13. Edge, S. B. et al. AJCC Cancer Staging Manual. 7th ed. New York: Springer 2010.

14. GeoDa. release 1.12.1.131.

15. Pedersen, A. B. et al. Missing data and multiple imputation in clinical epidemiological research. Clin Epidemiol, Vol. 9, 157-166 (2017).

16. StataCorp. Stata Statistical Software. College Station (TX: StataCorp LP, 2013). Release 13.

17. Rockberg, J. et al. Epidemiology of cutaneous melanoma in Sweden-Stage-specific survival and rate of recurrence. Int $J$ Cancer, Vol. 139, 122722-122729 (2016). 
18. Colombino, M. et al. Comparison of BRAF Mutation Screening Strategies in a Large Real-Life Series of Advanced Melanoma Patients. J Clin Med, Vol. 9, 82430 (2020).

19. Ferlay, J. et al. GLOBOCAN 2012 v1.0 Cancer Incidence and Mortality Worldwide. Lyon, France:IARC CancerBase.11.

20. Matthews, N. H., Li, W-Q., Qureshi, A. A., Weinstock, M. A. \& Cho, E. Epidemiology of Melanoma.Cutaneous Melanoma: Etiology and Therapy. 2018.

21. Moreira, J., Moreira, E., Azevedo, F. \& Mota, A. Melanoma Maligno Cutâneo: Estudo Retrospetivo de Sete Anos (20062012). Acta Med Port, Vol. 27, 4480 (2014).

22. Padrik, P., Valter, A., Valter, E., Baburin, A. \& Innos, K. Trends in incidence and survival of cutaneous malignant melanoma in Estonia: a population-based study. Acta Oncol (Madr), Vol. 56 (1), 52-58 (2017).

23. Steglich, R. B. et al. da SC. Epidemiological and histopathological aspects of primary cutaneous melanoma in residents of Joinville, 2003-2014. An Bras Dermatol. 2018, Vol. 93, 1, pp. 45-53.

24. Dummer, R., Hauschild, A., Lindenblatt, N., Pentheroudakis, G. \& Keilholz, U. Cutaneous melanoma: ESMO Clinical Practice Guidelines for diagnosis, treatment and follow-up. Ann Oncol, Vol. 30, 121884-121901 (2015).

25. Comprehensive, N. \& Network, C. NCCN Clinical Practice Guidelines in Oncology (NCCN Guidelines®) Melanoma.J Natl Compr Canc Netw.2013.

26. Cheng, L., Lopez-Beltran, A., Massari, F., Maclennan, G. T. \& Montironi, R. Molecular testing for BRAF mutations to inform melanoma treatment decisions: A move toward precision medicine. Mod Pathol, Vol. 31 (1), 24-38 (2018).

27. Nielsen, L. B. et al. Concordance in BRAF V600E status over time in malignant melanoma and corresponding metastases. Histopathology, Vol. 72, 5814-5825 (2018).

28. Lyubchenko, L. et al. The BRAF V600E mutation in singleinstitution study of Russian melanoma patients. Cancer Biomarkers, Vol. 16, 1153-1160 (2016).

29. Si, L. et al. Prevalence of BRAF V600E mutation in Chinese melanoma patients: Large scale analysis of BRAF and NRAS mutations in a 432-case cohort. Eur J Cancer, Vol. 48 (1), 94-100 (2012).

30. Sheen, Y. S. et al. Prevalence of BRAF and NRAS mutations in cutaneous melanoma patients in Taiwan. J Formos Med Assoc, Vol. 115, 2121-2127 (2016).

31. Verdasca, J., Costa, F. A., Ramos, C., Murteira, R. \& Miranda, A. The South Region Cancer Registry: an evaluation of its exhaustiveness in a cohort of lung cancer patients. Thorac Cancer. 2019, Vol. 10, 2, pp. 330-334.

\section{Figures}




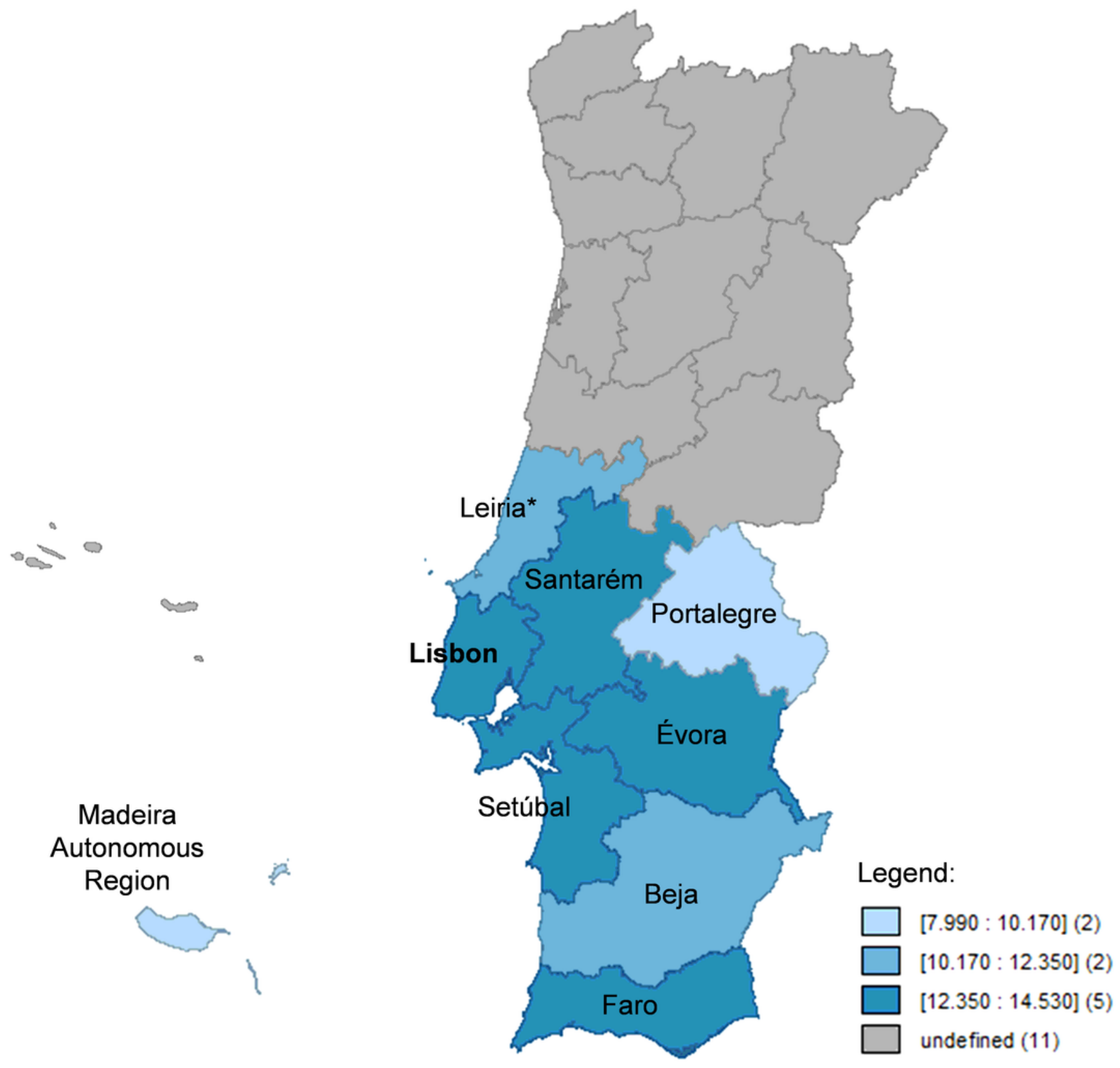

Figure 1

Cumulative incidence rate of cutaneous melanoma at 18 months in ROR-Sul 
(A)

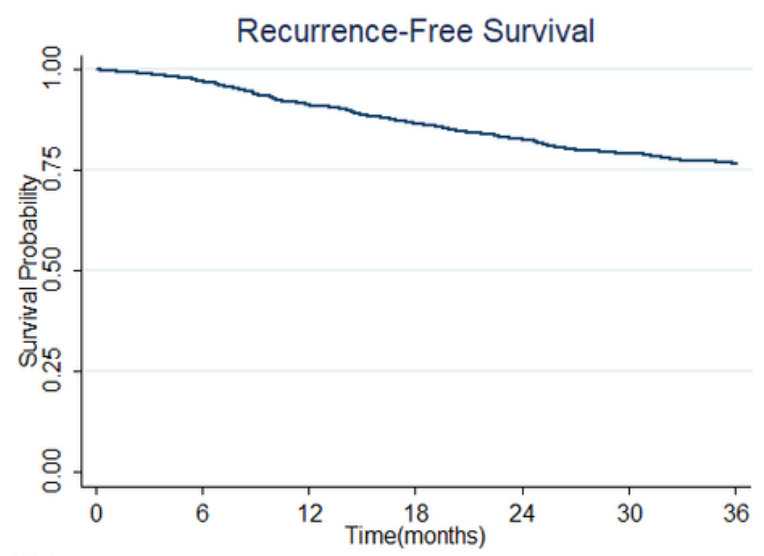

Number at risk

(Events)

742 (22) 717 (44) 673 (35) 636 (28) 606 (27) 577 (18) 535
(B)

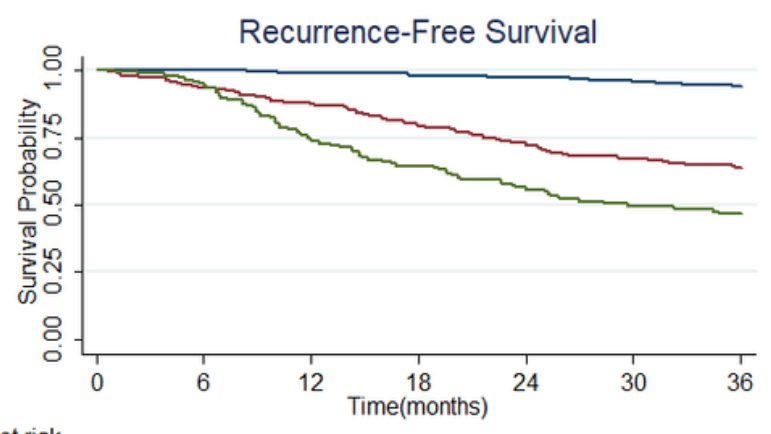

Number at risk

(Events)

I $391 \quad$ (1) 387 (3) 384 (4) 378 (3) 373 (6) 366 (7) 338

|| 216 (14) 202 (14) 188 (17) 171 (14) 157 (12) 144 (7) 134

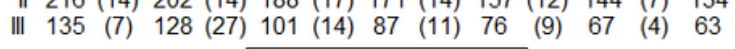

\section{Figure 2}

Recurrence-free survival of cutaneous melanoma in ROR-Sul (A: overall; B: by stage)

(A)

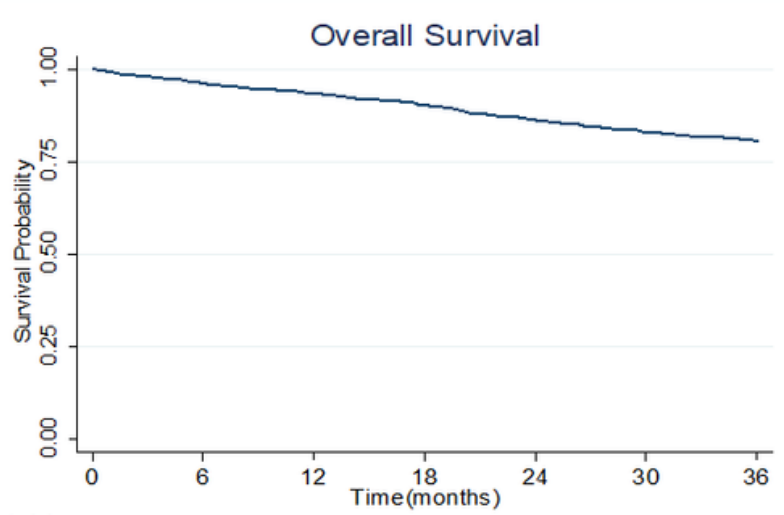

Number at risk

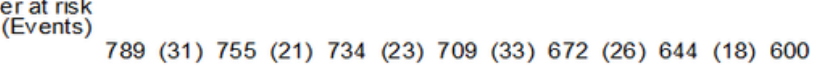

(B)

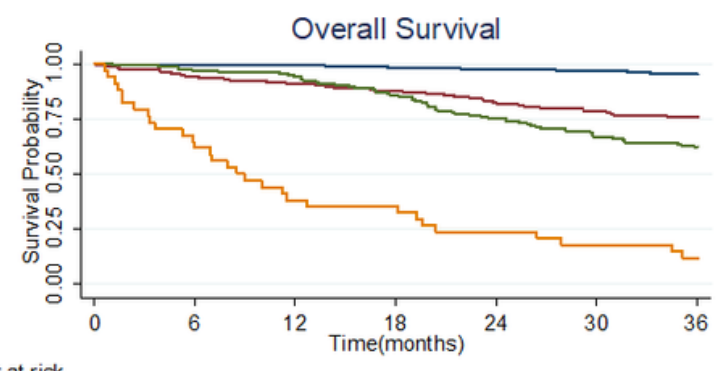

Number at risk

(Events)

$\begin{array}{lllllllll}1 & 391 & \text { (1) } 387 & \text { (2) } 385 & \text { (3) } 380 & \text { (3) } 375 & \text { (4) } 370 & \text { (5) } 344\end{array}$

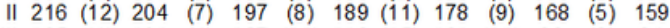
III $135 \quad$ (4) 131 (4) 127 (11) 116 (15) 101 (11) 90 (6) 84

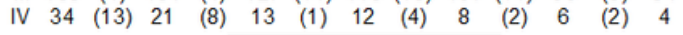

\begin{tabular}{rl|}
\hline I & - II \\
\hline IIV
\end{tabular}

\section{Figure 3}

Overall survival of cutaneous melanoma in ROR-Sul (A: overall; B: by stage) 